Case Report A four-month-old girl with Klebsiella pneumoniae febrile urinary tract infection (UTI) was diagnosed by ceVUS with VUR grade II on the right kidney. The appearance of contrast microbubbles outside the contours of the channel system and the entry of contrast into the renal parenchyma showed that the girl had IRR in the lower pole of the right kidney. A 99m Tc 2.3-dimercaptosuccinic acid (DMSA) renal scan, which was performed 8 months after the UTI, revealed a small scar on the lower pole of the right kidney, where IRR was found by ceVUS.

Conclusion Our case report showed that not only the grade of reflux but also the presence of IRR is important to predict the severity of the clinical picture and the development of possible scarring. It is important to find IRR because it may cause renal scars. VUR with IRR should be managed actively to decrease the chances of renal scarring or the development of new scars.

\section{A CASE REPORT OF AN INFANT WITH IDIOPATHIC HYPERCALCIURIA AND NEPHROLITHIASIS ASSOCIATED WITH CYP24A1 ENZYME POLYMORPHISM}

Ivana Trutin*, Iva Škorić. Klinika za pedijatriju, Klinički bolnički centar Sestre milosrdnice Zagreb, Hrvatska

\subsection{6/archdischild-2021-europaediatrics.377}

CYP24A1 is an enzyme that inactivates vitamin D and encodes vitamin D 24-hydroxylase. Mutations in this enzyme have been linked with idiopathic infantile hypercalcemia, nephrolithiasis, and nephrocalcinosis. The genetic testing for this mutation should be considered in the presence of calciuria, elevated serum calcium, elevated 1,25- dihydroxyvitamin D, and suppressed parathyroid hormone.

We present a previously healthy eight-month-old male infant with macroscopic hematuria. He was born full-term with no perinatal risks. Infant was breastfed for up to four months, and afterwards fed with milk formula, some mixed fruits and vegetables, supplemented with vitamin D according to the recommendations. The family history was negative for nephrolithiasis and urinary tract abnormalities. On the admission, he was in good general condition, afebrile, with normal vital parameters. His body weight was $8.05 \mathrm{~kg}$ (15th centile), length $76 \mathrm{~cm}$ (94th centile), and head circumference $46.1 \mathrm{~cm}$ (77th centile), without any deviations in his clinical examination. In laboratory findings, there were 90\% dysmorphic erythrocytes in urine and elevated calcium/creatinine ratio (1.5 $\mathrm{mmol} / \mathrm{mmol}, 2.1 \mathrm{mmol} / \mathrm{mmol})$. 24- hour urine sample showed hypercalciuria $(6 \mathrm{mg} / \mathrm{kg} / 24 \mathrm{~h})$ and albuminuria $(54 \mathrm{mg} / 24 \mathrm{~h})$. The values of alpha-1-microglobulin, parathyroid hormone, vitamin $\mathrm{D}$, serum electrolytes, antinuclear antibody, anti-neutrophil cytoplasmic antibodies, amino acids, glycols, oxalates and citrates in urine and coagulation tests were normal. Immunoglobulin blood test, C3, and C4 levels were normal. The urinary tract ultrasound revealed kidney stone of $6 \mathrm{~mm}$ in diameter in the middle cup of the left kidney. Genetic testing excluded suspected Dent's disease but confirmed heterozygous missense variant CYP24A1 c.469C >T, p.(Arg157Trp) classified as a polymorphism. He was treated with hydrochlorothiazide $(1 \mathrm{mg} / \mathrm{kg})$ with the recommendation of increased fluid intake with higher citrate content and a low-salt diet. Given the findings of genetic testing, we omitted vitamin D supplementation. Initially we had a good therapy response, but considering relapse of hypercalciuria after lowering the dose of hydrochlorothiazide $(0.5 \mathrm{mg} / \mathrm{kg})$ and known risk of non-melanoma skin cancer in patients on hydrochlorothiazide, the therapy was changed to potassium citrate $(2 \mathrm{mmol}$ potassium ion $/ \mathrm{kg} /$ day). During the follow-up, there was no relapse of macrohematuria, the infant was in good general condition with all tests within reference values. The ultrasound of the urinary tract remained unchanged.

Children presenting with hypercalcemia, hypercalciuria and nephrolithiasis should be tested because of the importance of recognition, genetic diagnosis and proper treatment of CYP24A1 mutations that can present with a wide range of phenotypic presentations, from asymptomatic to chronic renal disease.

\section{HYPERTENSIVE CRISIS IN A 16-YEAR OLD GIRL WITH ACCESSORY RENAL ARTERY: A CASE REPORT}

Bernardica Valent Morić ${ }^{*}$ Tomislav Krpan, Ivana Trutin, Josipa Josipović. KBC Sestre milosrdnice

\subsection{6/archdischild-2021-europaediatrics.378}

Introduction The most common pattern of kidney vascularisation is a single renal artery originating from the abdominal aorta. However, in $20-30 \%$ of general population an accessory renal artery can be found being more frequently present (up to $80 \%$ ) in patients with essential hypertension.

A possible pathomechanism of hypertension is the impaired renal perfusion since the diametar of a single renal artery is usually larger than when multiple arteries are present. Whether an accessory renal artery could be a cause of hypertension is still controversial.

Case Presentation We describe a case of a 16-year old girl who presented with hypertension crisis. She was previously healthy with no record of abnormal blood pressure (BP).

At admission she reported nausea and severe headache while her BP was 220/120 mmHg. Her body mass index was normal and physical examination unremarkable.

Initial workup showed normal renal function with normal serum electolytes and plasma glucose. Urin dipstick and urin toxicology screen were also normal. She had hypercholesterolemia and mild proteinuria but no signs of other target organ damage (electrocardiogram, echocardiography, fundoscopy and computed tomography of the brain were normal). Ambulatory blood pressure monitoring confirmed severe ambulatory hypertension.

Further evaluation was aimed at determining the possible cause of secondary hypertension. Urine metanephrines, urinary free cortisol, plasma cortisol, ACTH and thyroid function tests were within reference ranges. High normal plasma renin with elevated plasma aldosteron led to a suspicion of renovascular hypertension.

Magnetic resonance imaging revealed no pathology of the adrenal glands. Although renal ultrasonography with Doppler was normal, magnetic resonance angiography and later CT angiography showed two nonstenotic right renal arteries.

Conclusion Although nonstenotic, an accessory renal artery should be considered as a possible cause of renovascular hypertension in children and adolescents. 